\title{
Hydrosilylation of alkynes catalysed by platinum on titania
}

\author{
Francisco Alonso $^{\mathrm{a}, *}$, Robinson Buitrago ${ }^{\mathrm{b}}$, Yanina Moglie ${ }^{\mathrm{a}}$, Javier Ruiz-Martínez ${ }^{\mathrm{b}}$, \\ Antonio Sepúlveda-Escribano ${ }^{\mathrm{b}, *}$, Miguel Yus ${ }^{\mathrm{a}}$ \\ ${ }^{a}$ Departamento de Química Orgánica, Facultad de Ciencias, and Instituto de Síntesis Orgánica (ISO), Universidad de Alicante, Apdo. 99, E-03080 Alicante, Spain \\ ${ }^{\mathrm{b}}$ Departamento de Química Inorgánica, Facultad de Ciencias, and Instituto Universitario de Materiales (IUMA), Universidad de Alicante, Apdo. 99, E-03080 Alicante, Spain
}

\section{A R T I C L E I N F O}

\section{Article history:}

Received 2 August 2010

Received in revised form

29 September 2010

Accepted 29 September 2010

\begin{abstract}
A B S T R A C T
The heterogeneous hydrosilylation of alkynes catalysed by platinum on titania is reported. A variety of hydrosilanes react with both terminal and internal alkynes to furnish the corresponding vinyl silanes in high yields and short reaction times as well as in a regio- and stereoselective manner. The catalyst can be easily recovered and reused in several consecutive cycles.
\end{abstract}

(c) 2010 Elsevier B.V. All rights reserved.

Keywords:

Hydrosilylation

Alkynes

Platinum

Titania

Heterogeneous catalysis

\section{Introduction}

Vinyl silanes are very versatile organosilicon compounds with manifold applications in organic synthesis [1]. There is a general upsurge of interest in these organometalloids due to their particular non-toxicity, high chemical stability and low molecular weight when compared with other organometallic reagents. In fact, the transition-metal catalysed cross-coupling reaction with vinyl and aryl halides is one of the major applications of this type of compounds [2], which are advantageous with respect to the organotin, organoboron, and organozinc counterparts. The hydrosilylation of alkynes represents the most straightforward and convenient route to the preparation of vinyl silanes since proceeds with $100 \%$ atom efficiency [3-7]. A general difficulty encountered in the transition-metal catalysed addition of heteroatom-hydrogen bonds across the carbon-carbon triple bond [8], and in the hydrosilylation in particular [9], is the control of the regio- and stereochemistry of the process. The final outcome of the reaction depends on the catalyst, the alkyne, and the silane employed.

Among the different catalysts, platinum catalysts are usually preferred over other metals $[10,11]$ because of their selectivity and tolerance toward a wide range of functionalities. Most of the hydrosilylations are carried out under homogeneous conditions [12]

\footnotetext{
* Corresponding authors.

E-mail address: falonso@ua.es (F. Alonso).
}

(e.g. with platinum-phosphine complexes) while the heterogeneous version of this reaction has been somewhat neglected. Heterogeneous catalysts offer several advantages over the homogeneous counterparts, such as easy recovery, easy recycling, and enhanced stability $[13,14]$. To the best of our knowledge, only three reports describe the heterogeneous platinum-catalysed hydrosilylation of alkynes, involving platinum on carbon [15], platinum on silica [16], and unsupported platinum oxide [17]. Although high yields and good selectivities were generally achieved, an inert atmosphere was mandatory and the catalysts could not be reused. Due to our ongoing interest on supported platinum catalysts and their application to organic transformations [18,19], we want to present herein the selective hydrosilylation of alkynes catalysed by a reusable platinum-on-titania catalyst.

\section{Results and discussion}

The platinum catalysts were prepared by the impregnation method (see the Experimental section) and characterised by XRD and XPS. XRD analysis of the $\mathrm{Pt} / \mathrm{TiO}_{2}$ and $\mathrm{Pt} / \mathrm{CeO}_{2}$ catalysts did not provide any concluding information except that relative to the support diffraction peaks, due to the low metal loading and its high dispersion. The XPS spectra in the Pt $4 \mathrm{f}$ region is similar for both catalysts. Two broad bands appear which correspond to the $\mathrm{Pt}_{4} \mathrm{f}_{7 / 2}$ and $\mathrm{Pt}_{4 \mathrm{f}} \mathrm{f}$ levels. The $\mathrm{Pt}_{4} \mathrm{f}_{7 / 2}$ peak was deconvoluted into two components, placed at 72.2 and $74.2 \mathrm{eV}$ for the $\mathrm{Pt} / \mathrm{TiO}_{2}$ catalyst and at 72.6 and $73.9 \mathrm{eV}$ for the $\mathrm{Pt} / \mathrm{CeO}_{2}$ catalyst. The accurate assignment of

0022-328X/\$ - see front matter (c) 2010 Elsevier B.V. All rights reserved. doi:10.1016/j.jorganchem.2010.09.068 
the peaks is not easy, as the binding energies of the core electrons are affected not only by the metal oxidation state but also by the ligand atoms to which they are coordinated. For instance, the binding energy of the $\mathrm{Pt}_{4} \mathrm{f}_{7 / 2}$ level for Pt (IV) coordinated to six chlorine atoms (as in the $\mathrm{H}_{2} \mathrm{PtCl}_{6}$ precursor compound) is about $75.3 \mathrm{eV}$ (for $\mathrm{K}_{2} \mathrm{PtCl}_{6}$ ), but it decreases to $74.8 \mathrm{eV}$ for $\mathrm{PtO}_{2}$ and to $74.2 \mathrm{eV}$ for $\mathrm{Pt}(\mathrm{OH})_{4}$. The $\mathrm{Pt}_{4} \mathrm{f}_{7 / 2}$ level for $\mathrm{PtCl}_{2}$ is about $73.4 \mathrm{eV}$, whereas that for $\mathrm{Pt}(\mathrm{OH})_{2}$ is about $72.4 \mathrm{eV}$. Nonetheless, it can be concluded that platinum is in oxidised states in both calcined catalysts.

The hydrosilylation of phenylacetylene with triethylsilane was selected as the model reaction in order to optimise the conditions. Two different temperatures, solvents, and supports were used as parameters with the results being shown in Table 1 . The solventless reaction in the presence of the $\mathrm{Pt} / \mathrm{TiO}_{2}$ catalyst gave much better conversion and selectivity (entry 3 ) in a shorter reaction time than the reactions performed in THF or water (entries 1 and 2, respectively). The reactions proved to be slower when ceria was used as the support for platinum. Interestingly, in this case the regioselectivity of the reaction was reversed in THF and water (entries 4 and 5, respectively) with a low conversion, while the solventless process was quantitative but non selective (entry 6). Focussed on the $\mathrm{Pt} / \mathrm{TiO}_{2}$ catalyst, we observed that the reaction could be carried out at room temperature, although a longer reaction time was required with a concomitant loss of selectivity (entry 7). The reaction at room temperature in water failed to give the starting materials (entry 8). Near quantitative isolated yield and the highest selectivity toward the $\beta$-isomer were obtained by decreasing the amount of catalyst up to $50 \mathrm{mg}$ (entry 9). To the best of our knowledge, this represents the highest selectivity and yield achieved for the hydrosilylation of phenylacetylene with triethylsilane under heterogeneous conditions. A further decrease in the catalyst amount, however, was shown to be detrimental for the selectivity (entry 11). Finally, a blank experiment in the absence of the catalyst gave no products but the starting materials, thus demonstrating the crucial role of platinum in these hydrosilylation reactions.

The optimised reaction conditions (Table 1, entry 9) were extended to a variety of alkynes and hydrosilanes (Scheme 1 and Table 2). Some control experiments at room temperature have been also included for comparison purposes. We studied first the hydrosilylation of terminal aryl acetylenes with three different silanes (entries 1-6). The outcome of the hydrosilylation of

$$
\mathrm{R}^{1} \equiv+\mathrm{R}_{3}^{2} \mathrm{SiH} \quad \stackrel{\mathrm{Pt} / \mathrm{TiO}_{2}(0.25 \mathrm{~mol} \%)}{70^{\circ} \mathrm{C}, 0.5-1 \mathrm{~h}} \underset{\substack{\mathrm{R}^{1} \\ \beta \text {-trans isomer }}}{\stackrel{\mathrm{SiR}^{2}{ }_{3}}{\mathrm{R}^{1}}+\underset{\alpha \text { isomer }}{\mathrm{R}_{3}^{2} \mathrm{Si}}}
$$

Scheme 1. Optimised reaction conditions for the platinum-catalysed hydrosilylation of alkynes.

phenylacetylene with triphenylsilane was very similar to that with triethylsilane as regards both yield and selectivity (entry 2). Trimethoxysilane, however, gave lower selectivity irrespective of the reaction temperature, albeit the reactions were fast and high yielding in both cases (entry 3 ). The presence of electron-neutral or donating substituents at the 4-position of the arylacetylene gave better $\beta$-selectivity than that with electron-withdrawing substituents (entries 4-6). In the latter case, not only the selectivity but also the yields were slightly lower independently of the reaction temperature (entry 6). The terminal aliphatic alkyne oct-1-yne was subjected to catalytic hydrosilylation with both triethylsilane and triphenylsilane giving very similar results (entries 7 and 8). A decrease in the selectivity was observed in the addition of triethylsilane to functionalised terminal alkynes either at $70^{\circ} \mathrm{C}$ or room temperature (entries 9-11). Nevertheless, high yields of the corresponding products were obtained either for the $\alpha, \beta$-unsaturated alkyne ethyl propiolate and propargylic tertiary alcohol 1-ethynylcyclohexanol (entries 9 and 10, respectively). We must point out that the reaction of trimethylsilylacetylene with triphenylsilane was much more selective toward the $\beta$-isomer than that with triethylsilane, very probably due to steric reasons (entries 11 and 12). Nonetheless, the regioselectivity of the latter ( $\beta$-trans/ $\alpha \quad 62: 38$ ) greatly differs from that reported with $\mathrm{Pd} / \mathrm{C}$, where the $\beta$-cis isomer was formed instead of the $\alpha$ isomer ( $\beta$-trans $\beta$-cis 74:26). An interesting non-symmetric 1,2-disilylated ethylene was synthesized in the former case (entry 12). The hydrosilylation of symmetrically-substituted internal alkynes proved to be highly efficient furnishing the expected $(E)$-alkenylsilanes in near quantitative yield and short reaction time (entries 13-15). Unfortunately, the reaction of prop-1-yn-1-ylbenzene with triethylsilane was shown to be non-regioselective under the standard conditions (entry 16).

Table 1

Optimisation of the reaction conditions for the heterogeneous platinum-catalysed hydrosilylation of phenylacetylene with triethylsilane. ${ }^{\mathrm{a}}$

$$
\mathrm{Ph} \rightleftharpoons+\mathrm{Et}_{3} \mathrm{SiH} \underset{\mathrm{Ph}}{\stackrel{\mathrm{Pt} / \text { support }}{\text { conditions }}} \underset{\mathrm{Ph}}{=}
$$

\begin{tabular}{|c|c|c|c|c|c|c|}
\hline Entry & Catalyst & Solvent & $T\left({ }^{\circ} \mathrm{C}\right)$ & $t(\mathrm{~h})$ & Ratio $\beta / \alpha^{b}$ & Conversion $(\%)^{c}$ \\
\hline 1 & $\mathrm{Pt} / \mathrm{TiO}_{2}$ & THF & 70 & 6 & $52: 48$ & 42 \\
\hline 2 & $\mathrm{Pt} / \mathrm{TiO}_{2}$ & $\mathrm{H}_{2} \mathrm{O}$ & 70 & 6 & $52: 48$ & 84 \\
\hline 3 & $\mathrm{Pt} / \mathrm{TiO}_{2}$ & none & 70 & 1 & $94: 6$ & $100(96)$ \\
\hline 4 & $\mathrm{Pt} / \mathrm{CeO}_{2}$ & THF & 70 & 18 & $26: 74$ & 39 \\
\hline 5 & $\mathrm{Pt} / \mathrm{CeO}_{2}$ & $\mathrm{H}_{2} \mathrm{O}$ & 70 & 18 & $26: 74$ & 50 \\
\hline 6 & $\mathrm{Pt} / \mathrm{CeO}_{2}$ & none & 70 & 6 & $50: 50$ & $100(95)$ \\
\hline 7 & $\mathrm{Pt} / \mathrm{TiO}_{2}$ & none & r.t. & 6 & $79: 21$ & 96 \\
\hline 8 & $\mathrm{Pt} / \mathrm{TiO}_{2}$ & $\mathrm{H}_{2} \mathrm{O}$ & r.t & 24 & - & - \\
\hline 9 & $\mathrm{Pt} / \mathrm{TiO}_{2}{ }^{\mathrm{d}}$ & none & 70 & 1 & $92: 8$ & $100(97)$ \\
\hline 10 & $\mathrm{Pt} / \mathrm{TiO}_{2}{ }^{\mathrm{e}}$ & none & 70 & 1 & $74: 26$ & $100(96)$ \\
\hline 11 & none & none & 70 & 1 & - & - \\
\hline
\end{tabular}

a Phenylacetylene $(1 \mathrm{mmol})$ and triethylsilane $(1 \mathrm{mmol})$ in the solvent $(2 \mathrm{~mL})$ with $100 \mathrm{mg}$ of the supported catalyst (1 wt.\%), unless otherwise stated.

b Regioselectivity determined by GLC.

c Determined by GLC. Isolated yield in parenthesis.

d $50 \mathrm{mg}$ of catalyst were used (1 wt.\% Pt).

e $10 \mathrm{mg}$ of catalyst were used $(1 \mathrm{wt} . \% \mathrm{Pt})$. 
Table 2

Hydrosilylation of alkynes catalysed by $\mathrm{Pt} / \mathrm{TiO}_{2}{ }^{\mathrm{a}}$

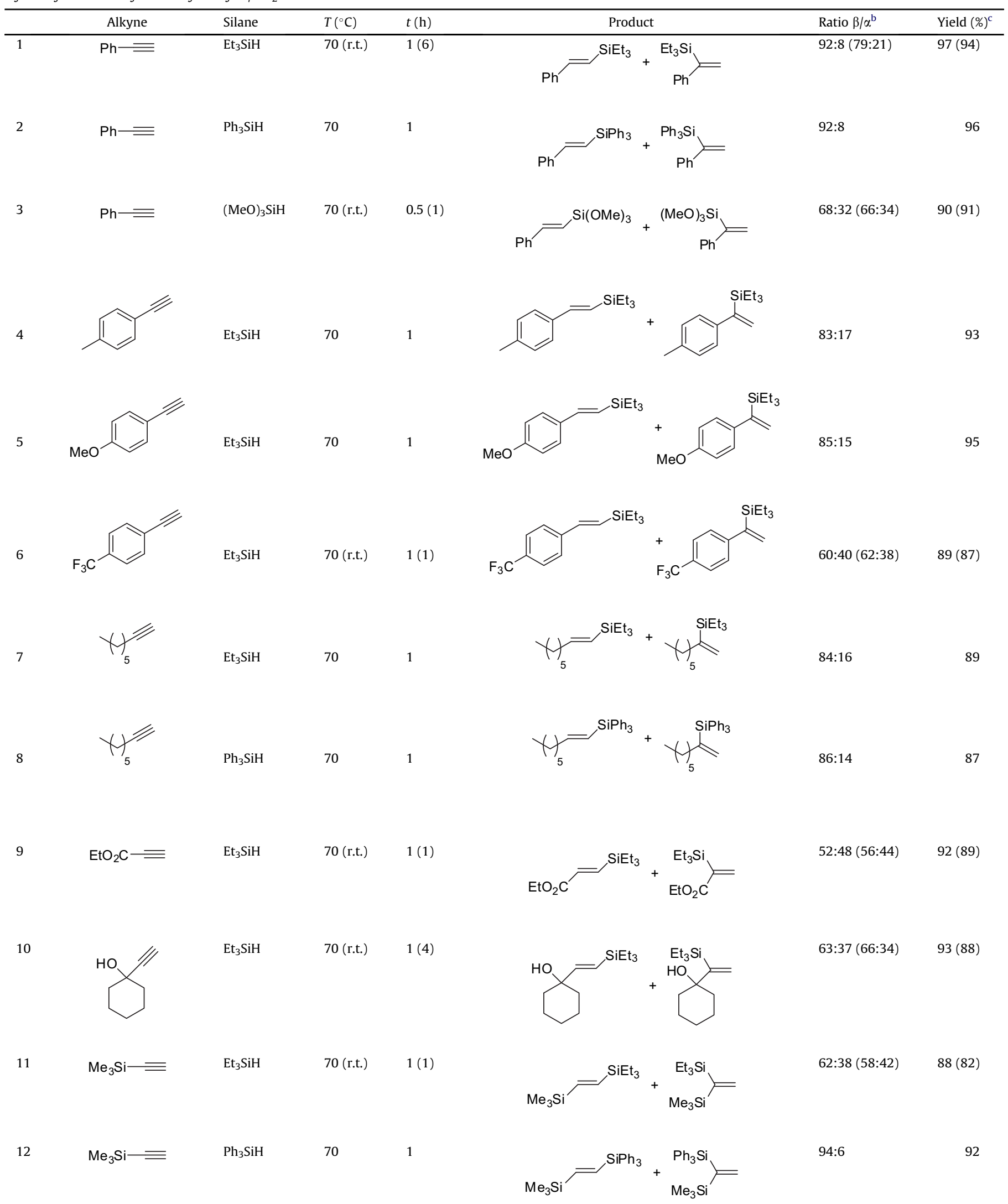

(continued on next page) 
Table 2 (continued)

\begin{tabular}{|c|c|c|c|c|c|c|c|}
\hline & Alkyne & Silane & $T\left({ }^{\circ} \mathrm{C}\right)$ & $t(\mathrm{~h})$ & Product & Ratio $\beta / \alpha^{b}$ & Yield $(\%)^{c}$ \\
\hline 13 & $\mathrm{Ph}=\mathrm{Ph}$ & $\mathrm{Et}_{3} \mathrm{SiH}$ & 70 & 1 & $\mathrm{SiEt}_{3}$ & - & 99 \\
\hline 14 & $\mathrm{Bu}^{\mathrm{n}}=\mathrm{Bu}^{\mathrm{n}}$ & $\mathrm{Et}_{3} \mathrm{SiH}$ & 70 & 1 & $\mathrm{SiEt}_{3}$ & - & 98 \\
\hline 15 & $\mathrm{Bu}^{\mathrm{n}}=\mathrm{Bu}^{\mathrm{n}}$ & $\mathrm{Ph}_{3} \mathrm{SiH}$ & 70 & 1 & $\mathrm{SiPh}_{3}$ & - & 98 \\
\hline 16 & $\mathrm{Ph}=\mathrm{Me}$ & $\mathrm{Et}_{3} \mathrm{SiH}$ & 70 & 1 & $\mathrm{Et}_{3}$ & $50: 50$ & 90 \\
\hline
\end{tabular}

\footnotetext{
a Alkyne ( $1 \mathrm{mmol})$, silane ( $1 \mathrm{mmol}$ ), and $\mathrm{Pt} / \mathrm{TiO}_{2}(50 \mathrm{mg}, 1 \mathrm{wt} \% \mathrm{Pt}, 0.25 \mathrm{~mol} \%)$. Data in parenthesis correspond to reactions performed at r.t.

b Regioselectivity determined by GLC.

c Isolated yield.
}

It is worthwhile mentioning that all reactions at $70{ }^{\circ} \mathrm{C}$ were accomplished in $\leq 1 \mathrm{~h}$ and that the $\beta$-cis isomer was not detected in any hydrosilylation of terminal alkynes. In addition, the catalyst could be easily recovered by filtration and reused without any pretreatment. Quantitative conversion was recorded in the hydrosilylation of dec-5-yne with triethylsilane along four consecutive runs, with a progressive decrease of activity that was more pronounced in the fifth cycle (Table 3 ). This behaviour could be rationalised in terms of catalyst deactivation, albeit a deleterious effect due to partial loss of catalyst during sampling, because of the slurry character of the reaction mixture, cannot be ruled out. At any rate, this represents, to the best or our knowledge, the first heterogeneous platinum-catalysed hydrosilylation of alkynes in which the catalyst is reused without any pre-treatment.

In conclusion, platinum on titania has been demonstrated to catalyse the hydrosilylation of terminal and internal alkynes, bearing aryl, alkyl, as well as different functional groups, with three different hydrosilanes to give the corresponding alkenylsilanes in high yields and short reaction times. Reactions are performed in the absence of solvent, proceeding with exclusive syn addition of the $\mathrm{Si}-\mathrm{H}$ bond across the carbon-carbon triple bond and a $\beta / \alpha$ regioselectivity of up to $94: 6$. In contrast to previously reported heterogeneous platinum catalysts, reactions proceed under air, even at room temperature, and the catalyst can be easily recovered and reused in several cycles. Further research to expand the substrate scope as well as on the hydrosilylation of alkynes with other supported catalysts is under way.

Table 3

Reutilisation of the $\mathrm{Pt} / \mathrm{TiO}_{2}$ catalyst in the hydrosilylation of dec-5-yne with triethylsilane.

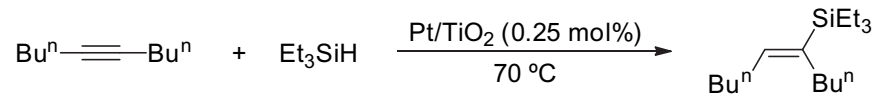

\begin{tabular}{lccccc}
\hline Run & 1 & 2 & 3 & 4 & 5 \\
\hline$t(\mathrm{~h})$ & 1 & 1 & 3 & 7 & 24 \\
Conversion (\%) & 98 & 98 & 97 & 98 & 62 \\
\hline
\end{tabular}

a Determined by GLC.

\section{Experimental}

\subsection{General methods}

The BET surface area of catalysts and supports was determined by nitrogen adsorption at $-196{ }^{\circ} \mathrm{C}$ with a Coulter Omnisorp 610 system. Before measurements, the samples were dried at $110^{\circ} \mathrm{C}$ for $12 \mathrm{~h}$ and out-gassed at $250{ }^{\circ} \mathrm{C}$ under vacuum. X-ray powder diffraction patterns were recorded on a JSO Debye-flex 2002 system, from Seifert, fitted with a Cu cathode and a Ni filter, using a $2^{\circ} \mathrm{min}^{-1}$ scanning rate. X-ray photoelectron spectra (XPS) were acquired with a VG-Microtech Multilab 3000 spectrometer equipped with a hemispherical electron analyser and a $\mathrm{Mg} \mathrm{K \alpha}$ ( $h=1253.6 \mathrm{eV}, 1 \mathrm{eV}=1.602 \times 10^{-19} \mathrm{~J}$ ) $300-\mathrm{W}$ X-ray source. All the starting alkynes and hydrosilanes were commercially available of the best grade (Aldrich, Acros, Alfa Aesar) and were used without further purification. NMR spectra were recorded on a Bruker Avance 300 spectrometer ( $300 \mathrm{MHz}$ for ${ }^{1} \mathrm{H}$ NMR and $75 \mathrm{MHz}$ for ${ }^{13} \mathrm{C}$ NMR); chemical shifts are given in $(\delta)$ parts per million and coupling constants $(J)$ in Hertz. Mass spectra (EI) were obtained at $70 \mathrm{eV}$ on an Agilent 5973 spectrometer (GC-MS); fragment ions in $\mathrm{m} / \mathrm{z}$ with relative intensities (\%) in parenthesis. HRMS analyses were carried out on a Finnigan MAT95S spectrometer. Thin-layer chromatography was carried out on TLC plastic sheets with silica gel $60 \mathrm{~F}_{254}$ (Merck). The purity of volatile compounds and the chromatographic analyses (GLC) were determined with a Hewlett Packard HP-6890 instrument equipped with a flame ionisation detector and a $30 \mathrm{~m}$ capillary column $(0.32 \mathrm{~mm}$ diameter, $0.25 \mu \mathrm{m}$ film thickness), using nitrogen $(2 \mathrm{~mL} / \mathrm{min})$ as carrier gas, $T_{\text {injector }}=270{ }^{\circ} \mathrm{C}, T_{\text {column }}=60^{\circ} \mathrm{C}(3 \mathrm{~min})$ and $60-270{ }^{\circ} \mathrm{C}\left(15^{\circ} \mathrm{C} /\right.$ $\min )$; retention times $\left(t_{\mathrm{r}}\right)$ are given in min.

\subsection{Preparation of the catalysts}

Degussa $\mathrm{P} 25 \mathrm{TiO}_{2}$ (60\% anatase, $40 \%$ rutile) with a surface area of $50 \mathrm{~m}^{2} \mathrm{~g}^{-1}\left(\mathrm{~N}_{2},-196{ }^{\circ} \mathrm{C}\right.$, BET method) was used as support, after being calcined in air at $500{ }^{\circ} \mathrm{C}$ for $5 \mathrm{~h}$. The $\mathrm{Pt} / \mathrm{TiO}_{2}$ catalyst was prepared by the impregnation method with an aqueous solution of $\mathrm{H}_{2} \mathrm{PtCl}_{6} \cdot 6 \mathrm{H}_{2} \mathrm{O}$ (Aldrich) of the appropriate concentration to achieve a Pt content of $1 \mathrm{wt} . \%$. The slurry ( $10 \mathrm{ml} \mathrm{g}^{-1}$ of support) was stirred 
for $12 \mathrm{~h}$ and then the excess of solvent was removed by heating at $90^{\circ} \mathrm{C}$ under vacuum in a rotary evaporator. Finally, the catalyst was dried at $110{ }^{\circ} \mathrm{C}$ for $24 \mathrm{~h}$ and calcined under a flow of synthetic air at $400{ }^{\circ} \mathrm{C}$ for $4 \mathrm{~h}$, with a heating rate of $5^{\circ} \mathrm{C} / \min [20,21]$.

The $\mathrm{CeO}_{2}$ support was prepared by the homogeneous precipitation method. An aqueous solution containing $\mathrm{Ce}\left(\mathrm{NO}_{3}\right)_{3} \cdot 6 \mathrm{H}_{2} \mathrm{O}$ (Aldrich, 99\%) and urea was gently heated under stirring. Urea decomposition produced a yellow precipitate that was filtered, washed with water, dried at $110^{\circ} \mathrm{C}$ overnight, and finally calcined at $450{ }^{\circ} \mathrm{C}$ for $2 \mathrm{~h}$. It had a BET surface are of $70 \mathrm{~m}^{2} \mathrm{~g}^{-1}$. The Pt $/ \mathrm{CeO}_{2}$ catalyst was prepared by impregnation of the support with an acetone solution of $\left[\mathrm{Pt}\left(\mathrm{NH}_{3}\right)_{4}\right]\left(\mathrm{NO}_{3}\right)_{2}$ (Aldrich), which allowed to load a $1 \mathrm{wt} . \%$ Pt. Excess of solvent was removed as described above and the sample was dried and calcined under the same conditions as for the $\mathrm{Pt} / \mathrm{TiO}_{2}$ catalyst.

\subsection{General procedure for the catalytic hydrosilylation of alkynes}

The alkyne $(1.0 \mathrm{mmol})$ and hydrosilane $(1.0 \mathrm{mmol})$ were added to a $20 \mathrm{~mL}$ reaction tube containing the $\mathrm{Pt} / \mathrm{TiO}_{2}$ catalyst $(50.0 \mathrm{mg}$, $0.25 \mathrm{~mol} \% \mathrm{Pt}$ ). The mixture was stirred at $70{ }^{\circ} \mathrm{C}$ for $1 \mathrm{~h}$ and the reaction course was monitored by TLC and/or gas chromatography until total conversion of the starting materials. Diethyl ether $(10 \mathrm{~mL})$ was added to the mixture, followed by catalyst filtration and washing with additional diethyl ether $(2 \times 10 \mathrm{~mL})$. The filtrate solvent was removed in vacuo to give the corresponding vinyl silanes. The recovered catalyst was dried under vacuum for removal of any residual solvent before reutilisation. Vinyl silanes in Table 2, entries 1 [15], 2 [22], 3 [23], 4 [24], 5 [24], 6 [24], 7 [25], 8 [25], 9 [26], 10 [22], 11 [15], 12 [27], 13 [15], and 16 [15], were characterised by comparison of their physical and spectroscopic data with those described in the literature. Data for the new compounds follow:

\subsection{1. (E)-Dec-5-en-5-yltriethylsilane (Table 2, entry 14)}

Yellow oil, 98\% yield, $R_{f} 0.89$ (hexane), $t_{\mathrm{r}} 12.06 \mathrm{~min}$. IR (neat): 2959, 2935, 2874, 1610, 1467, 1418, 1377, 1231, 1006, $713 \mathrm{~cm}^{-1} .{ }^{1} \mathrm{H}$ NMR (300 MHz, $\left.\mathrm{CDCl}_{3}\right): \delta 0.52-0.64(\mathrm{~m}, 6 \mathrm{H}), 0.86-0.98(\mathrm{~m}, 15 \mathrm{H})$, $1.22-1.41(\mathrm{~m}, 8 \mathrm{H}), 2.03-2.17(\mathrm{~m}, 4 \mathrm{H}), 5.68(\mathrm{t}, 1 \mathrm{H}, J=6.9 \mathrm{~Hz}) .{ }^{13} \mathrm{C}$ NMR $\left(75 \mathrm{MHz}, \mathrm{CDCl}_{3}\right): \delta 3.8\left(3 \times \mathrm{CH}_{2}\right), 8.0\left(3 \times \mathrm{CH}_{3}\right), 14.6,14.7$ $\left(2 \times \mathrm{CH}_{3}\right), 23.1,23.8,28.1,30.4,32.6,33.1\left(6 \times \mathrm{CH}_{2}\right), 137.8(\mathrm{C}), 142.5$ (CH). MS (EI): $m / z$ (\%) 254 (M+ , 2\%), 226 (21), 225 (100), 197 (23), 113 (11), 82 (32), 59 (24). HRMS (EI): $\mathrm{m} / z$ calcd. for $\mathrm{C}_{16} \mathrm{H}_{34} \mathrm{Si}$ 254.2430, found 254.2416.

\subsection{2. (E)-Dec-5-en-5-yltriphenylsilane (Table 2, entry 15)}

Yellow oil, 98\% yield, $R_{f} 0.66$ (hexane), $t_{\mathrm{r}} 20.06 \mathrm{~min}$ IR (neat): 3058, 2948, 2923, 2858, 1610, 1427, 1104, $696 \mathrm{~cm}^{-1} .{ }^{1} \mathrm{H}$ NMR $\left(300 \mathrm{MHz}, \mathrm{CDCl}_{3}\right): \delta 0.67,0.89(2 \mathrm{t}, 6 \mathrm{H}, J=6.7 \mathrm{~Hz}), 1.00-1.15(\mathrm{~m}, 4 \mathrm{H})$, $1.29-1.42(\mathrm{~m}, 4 \mathrm{H}), 2.15-2.28(\mathrm{~m}, 4 \mathrm{H}), 5.97(\mathrm{t}, 1 \mathrm{H}, J=6.9 \mathrm{~Hz})$, 7.23-7.42 (m, 9H), 7.51-7.60 (m, 6H). ${ }^{13} \mathrm{C} \mathrm{NMR} \mathrm{(75} \mathrm{MHz,} \mathrm{CDCl}_{3}$ ): $\delta$ 13.4, $13.7\left(2 \times \mathrm{CH}_{3}\right), 22.3,22.6,28.5,29.7,31.4,31.9\left(6 \times \mathrm{CH}_{2}\right), 127.3$, $128.9,136.1(15 \times \mathrm{CH}), 134.7,135.1(2 \times \mathrm{C}), 147.1\left(\mathrm{CHCH}_{2}\right)$. MS (EI): $\mathrm{m} / z$
(\%) 398 ( $\left.\mathrm{M}^{+}, 12 \%\right), 320$ (22), 260 (25), 259 (100), 183 (26), 181 (17). HRMS (EI): $m / z$ calcd. for $\mathrm{C}_{28} \mathrm{H}_{34} \mathrm{Si} 398.2430$, found 398.2443.

\section{Acknowledgements}

This work was generously supported by the Spanish Ministerio de Ciencia e Innovación (MICINN; grant no. CTQ2007-65218, Consolider Ingenio 2010-CSD2007-00006) and the Generalitat Valenciana (GV; PROMETEO/2009/039 and PROMETEO/2009/002). Y.M. thanks the Vicerrectorado de Investigación, Desarrollo e Innovación of the University of Alicante for a grant. R.B. acknowledges the University of Alicante, CAM and Union Fenosa for his grant (UF2007-X9159987F).

\section{References}

[1] K. Oshima, in: I. Fleming (Ed.), Science of Synthesis, vol. 4, Georg Thieme Verlag, Stuttgart, 2002, pp. 713-756.

[2] S.E. Denmark, M.H. Ober, Aldrichimica Acta 36 (2003) 75-85.

[3] I. Ojima, Z. Li, J. Zhu (Part 2), in: Z. Rappoport, Y. Apeloig (Eds.), Chemistry of Organic Silicon Compounds, vol. 2, vCH, Weinheim, 1998, pp. 1687-1792.

[4] B. Marciniec, Silicon Chem. 1 (2002) 155-175.

[5] B.M. Trost, Z.T. Ball, Synthesis (2005) 853-887.

[6] A.K. Roy, Adv. Organomet. Chem. 55 (2008) 1-59.

[7] B. Marciniec, H. Maciejewski, C. Pietraszuk, P. Pawluc, in: B. Marciniec (Ed.), Hydrosilylation: A Comprehensive Review on Recent Advances, Advances in Silicon Science Series, vol. 1, Springer, 2009 (Chapter 2).

[8] F. Alonso, I.P. Beletskaya, M. Yus, Chem. Rev. 104 (2004) 3079-3159.

[9] C.J. Herzig, in: N. Auner, J. Weis (Eds.), Organosilicon Chemistry, VCH, Weinheim, 1994, pp. 253-260.

[10] For ruthenium catalysis, see for instance: J.L. Vivero-Escota, L.K. Wo, Chemtracts 19 (2006) 358-366.

[11] For early transition-metal catalysis, see: F. Bao, K. Kanno, T. Takahashi, Trends Org. Chem 12 (2008) 1-17.

[12] See, for instance: G. Berthon-Gelloz, I.E. Markó, in: S.P. Nolan (Ed.), $\mathrm{N}$-Heterocyclic Carbenes in Synthesis, Wiley, Weinheim, 2006, pp. 119-161.

[13] J.A. Anderson, M. Fernández García (Eds.), Supported Metals in Catalysis, Imperial College Press, London, 2005.

[14] K. Kaneda, K. Ebitani, T. Mizugaki, K. Mori, Bull. Chem. Soc. Jpn. 79 (2006) 981-1016.

[15] M. Chauhan, B.J. Hauck, L.P. Keller, P. Boudjouk, J. Organomet. Chem 645 (2002) $1-13$

[16] R. Jiménez, J.M. Martínez Rosales, J. Cervantes, Can. J. Chem. 81 (2003) $1370-1375$.

[17] A. Hamze, O. Provot, J.-D. Brion, M. Alami, Synthesis (2007) 2025-2036.

[18] F. Alonso, P. Riente, F. Rodríguez-Reinoso, J. Ruiz-Martínez, A. SepúlvedaEscribano, M. Yus, J. Catal. 260 (2008) 113-118.

[19] F. Alonso, P. Riente, F. Rodríguez-Reinoso, J. Ruiz-Martínez, A. SepúlvedaEscribano, M. Yus, ChemCatChem 1 (2009) 75-77.

[20] A. Huidobro, A. Sepúlveda-Escribano, F. Rodríguez-Reinoso, J. Catal. 212 (2002) 94-103.

[21] J. Silvestre-Albero, A. Sepúlveda-Escribano, F. Rodríguez-Reinoso, J.A. Anderson, J. Catal. 223 (2004) 179-190.

[22] H.A. Wei, J.G. Verkade, Organometallics 24 (2005) 2590-2596.

[23] C. Pietraszuk, B. Marciniec, H. Fischer, Organometallics 19 (2000) 913-917.

[24] A. Battace, T. Zair, H. Doucet, M. Santelli, J. Organomet. Chem 690 (2005) 3790-3802.

[25] M.R. Chaulagain, G.M. Mahandru, J. Montgomery, Tetrahedron 62 (2006) 7560-7566.

[26] Y. Seki, K. Takeshita, K. Kawamoto, S. Murai, N. Sonoda, J. Org. Chem. 51 (1986) 3890-3895.

[27] C.S. Kraihanzel, M.L. Losee, J. Organomet. Chem 10 (1967) 427-437. 